\title{
Effect Mechanism of Penstock on Stability and Regulation Quality of Turbine Regulating System
}

\author{
Wencheng Guo, Jiandong Yang, Jieping Chen, and Yi Teng \\ State Key Laboratory of Water Resources and Hydropower Engineering Science, Wuhan University, Wuhan 430072, China \\ Correspondence should be addressed to Wencheng Guo; wench24@126.com
}

Received 17 July 2014; Accepted 20 October 2014; Published 19 November 2014

Academic Editor: Hongbin Zhang

Copyright ( 2014 Wencheng Guo et al. This is an open access article distributed under the Creative Commons Attribution License, which permits unrestricted use, distribution, and reproduction in any medium, provided the original work is properly cited.

\begin{abstract}
This paper studies the effect mechanism of water inertia and head loss of penstock on stability and regulation quality of turbine regulating system with surge tank or not and proposes the construction method of equivalent model of regulating system. Firstly, the complete linear mathematical model of regulating system is established. Then, the free oscillation equation and time response of the frequency that describe stability and regulation quality, respectively, are obtained. Finally, the effects of penstock are analysed by using stability region and response curves. The results indicate that the stability and regulation quality of system without surge tank are determined by time response of frequency which only depends on water hammer wave in penstock, while, for system with surge tank, the time response of frequency depending on water hammer wave in penstock and water-level fluctuation in surge tank jointly determines the stability and regulation quality. Water inertia of penstock mainly affects the stability and time response of frequency of system without surge tank as well as the stability and head wave of time response of frequency with surge tank. Head loss of penstock mainly affects the stability and tail wave of time response of frequency with surge tank.
\end{abstract}

\section{Introduction}

Turbine regulating system is the core component of load frequency control (LFC) of hydropower system. When hydroelectric power plant (HPP) operates under isolated mode or becomes isolated from the grid, the regulating system should maintain adequate stability margins as well as certain regulation quality. Stability and regulation quality are two sides which are the unity of opposites of regulating system and are influenced by hydraulic, mechanical, and electrical factors [1]. Pipeline network is the foundation of hydraulic factors. As a key link of pipeline network, penstock has significant and unique effects on stability and regulation quality. Hence, a thorough and detailed understanding of effects of penstock is necessary for proper control of stability and regulation quality of turbine regulating system.

For the subject of stability and regulation quality, previous research centres upon governor. Many authors studied the working performance of temporary droop type governor [25] and proportional-integral-derivative (PID) type governor [6-10]. The adjustment of governor parameters was also researched [11]. As for penstock of HPP without surge tank, Ruud [12] investigated the instability of a hydraulic turbine with a very long penstock; Murty and Hariharan [13] analysed the influence of water column elasticity on the stability limits of hydroturbine generating unit with long penstock and proposed a modified water column compensator to enhance the stability regions and dynamic performance; Souza and Barbieri [14] discussed hydraulic transients in hydropower plants based on the nonlinear model of penstock and hydraulic turbine model; Sanathanan [15] proposed a method for obtaining accurate low order model for hydraulic turbine penstock; Krivehenko et al. [16] studied some special conditions of unit operation in hydropower plant with long penstocks. If a HPP has surge tank, its penstock is usually neglected to simplify the mathematical model of turbine regulating system $[17,18]$.

It can be found from the above summary that the previous research on the effects of penstock on stability and regulation quality forms two major limitations. Firstly, the research object is mainly the HPP which has long penstock and does not have surge tank. However, the most important factors 


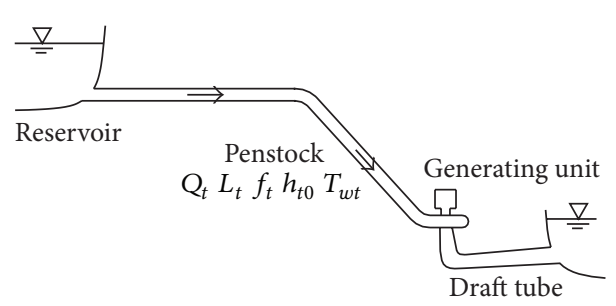

(a) Pipeline and power generating system (without surge tank)

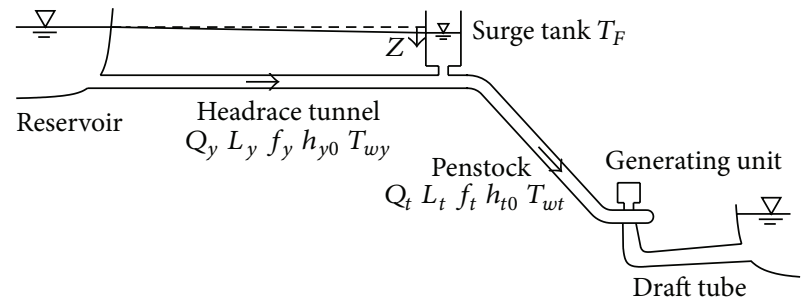

(b) Pipeline and power generating system (with surge tank)

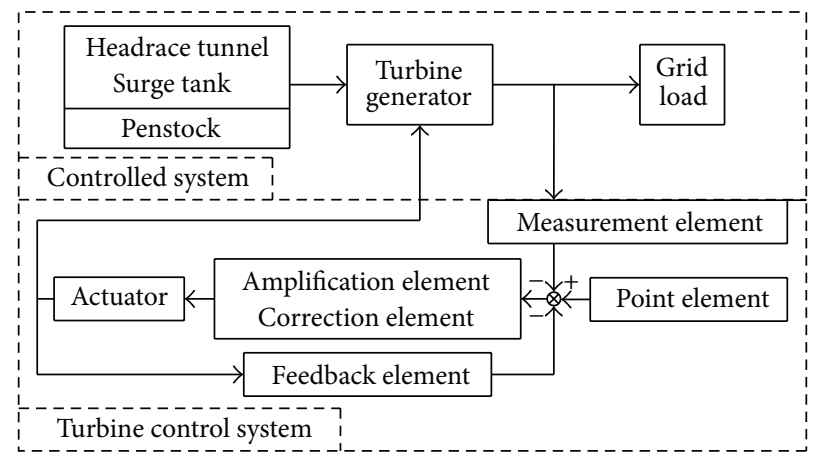

(c) Turbine regulating system

FIGURE 1: Turbine regulating system of isolated HPP with surge tank or not.

of penstock are water inertia and head loss. The effects of these two factors are not investigated and compared deeply. Secondly, there is only little research on HPP with surge tank. It is well recognized that surge tank is indeed an important measure of pressure reduction. Since the influence of waterlevel fluctuation in surge tank, the dynamic response of regulating system with surge tank is significantly different from the case without surge tank.

This paper aims to overcome the above two limitations and thoroughly study the effect mechanism of water inertia and head loss of penstock on stability and regulation quality of turbine regulating system with surge tank or not. It is assumed that the system operates on an isolated load and the water column is rigid. This paper is organized as follows. In Section 2, the complete linear mathematical model of turbine regulating system that includes all subsystems (i.e., headrace tunnel, surge tank, penstock, turbine, generator, and governor) is established, and the overall transfer functions of systems without surge tank and with surge tank are derived from the complete mathematical model under step load disturbance. In Sections 3 and 4, based on the free oscillation equation and time response of the frequency of system derived from overall transfer function, the effects of water inertia and head loss of penstock on stability and regulation quality are analysed by using stability region and response curves. In Section 5, the effect mechanism of penstock is epurated and summarized. Then according to this effect mechanism, the improvement methods of stability and regulation quality and construction method of equivalent model of regulating system are proposed.

\section{Mathematical Model}

The turbine regulating system of isolated HPP with surge tank or not is illustrated in Figure 1.

2.1. Basic Equations. The HPP without surge tank can be regarded as a special case of HPP with surge tank when the length of headrace tunnel and the sectional area of surge tank are both 0 . Hence, in this section, the complete mathematical model of turbine regulating system of isolated HPP with surge tank is first established, and then the model of that without surge tank can be obtained as a special case.

\subsubsection{Turbine Regulating System of Isolated HPP with Surge Tank}

(1) Controlled System [19, 20]. Momentum equation of headrace tunnel:

$$
z=T_{w y} \frac{d q_{y}}{d t}+\frac{2 h_{y 0}}{H_{0}} q_{y}
$$

Continuity equation of surge tank:

$$
q_{y}=q_{t}-T_{F} \frac{d z}{d t} .
$$

Momentum equation of penstock:

$$
h=-T_{w t} \frac{d q_{t}}{d t}-\frac{2 h_{t 0}}{H_{0}} q_{t}-z .
$$




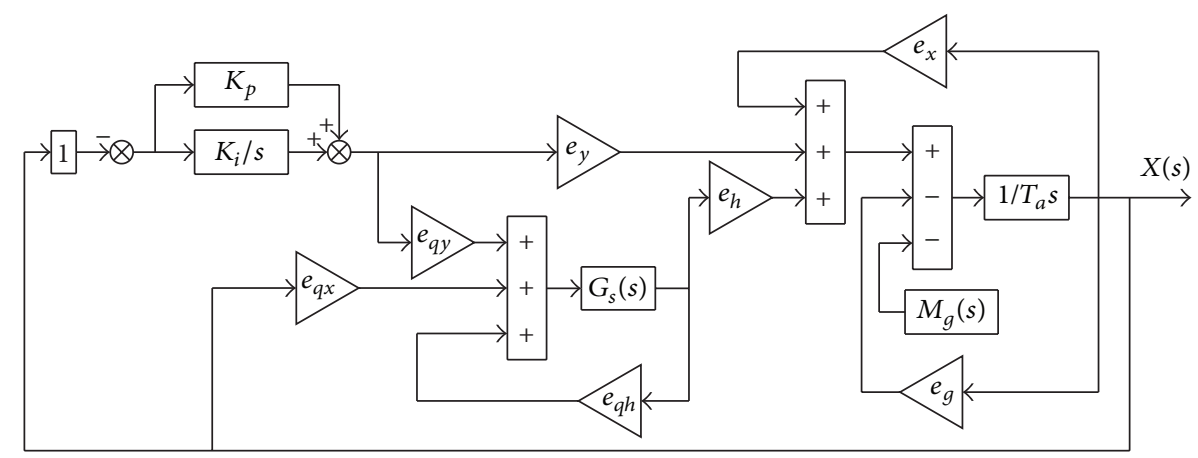

(a) Overall block diagram of turbine regulating system

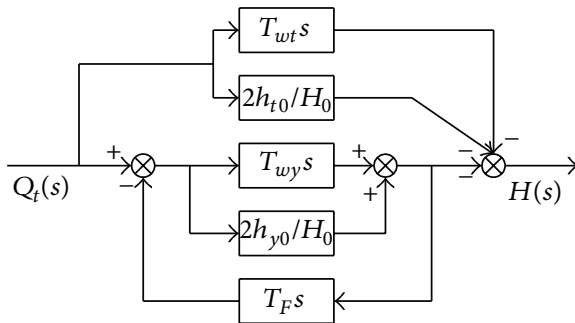

(b) Block diagram of pipeline system (with surge tank)

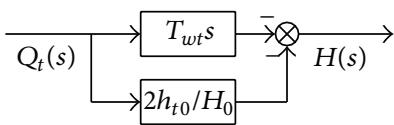

(c) Block diagram of pipeline system (without surge tank)

FIGURE 2: Block diagram of turbine regulating system.

Moment equation and discharge equation of turbine:

$$
\begin{gathered}
m_{t}=e_{h} h+e_{x} x+e_{y} y, \\
q_{t}=e_{q h} h+e_{q x} x+e_{q y} y .
\end{gathered}
$$

First derivative differential equation of generator:

$$
T_{a} \frac{d x}{d t}=m_{t}-\left(m_{g}+e_{g} x\right) .
$$

(2) Turbine Control System [19, 20]. Equation of governor:

$$
\frac{d y}{d t}=-K_{p} \frac{d x}{d t}-K_{i} x .
$$

The nomenclatures in (1)-(6) are presented in Appendix A.

2.1.2. Turbine Regulating System of Isolated HPP without Surge Tank. Delete (1) and (2) and reformulate (3) to the following form:

$$
h=-T_{w t} \frac{d q_{t}}{d t}-\frac{2 h_{t 0}}{H_{0}} q_{t} .
$$

Then (7), (4)-(6) are the complete mathematical model of turbine regulating system of isolated HPP without surge tank. Note that this model (see (7), (4)-(6)) can as well be obtained from (1)-(6) in the conditions of $T_{w y}=0, h_{y 0}=0$, and $T_{F}=0$.

2.2. Overall Transfer Function. For the situation of load disturbance, the block diagram of turbine regulating system is determined by the basic equations in Section 2.1 and shown in Figure 2, where $G_{s}(s)=H(s) / Q_{t}(s)$ is the transfer function of pipeline system and can be derived from the Laplace transforms of (1)-(3) for HPP with surge tank and (7) for HPP without surge tank. $s$ is complex variable.

According to Figures 2(a) and 2(b) and the Laplace transforms of (1)-(6), the following overall transfer function of turbine regulating system of isolated HPP with surge tank is obtained:

$$
G(s)=\frac{X(s)}{M_{g}(s)}=-\frac{s\left(b_{0} s^{3}+b_{1} s^{2}+b_{2} s+b_{3}\right) / K_{i}}{a_{0} s^{5}+a_{1} s^{4}+a_{2} s^{3}+a_{3} s^{2}+a_{4} s+a_{5}},
$$

where $M_{g}(s)$ and $X(s)$ are the Laplace transforms of load disturbance $m_{g}$ and time response of the frequency $x$, respectively, and the former is input signal and the later is output signal. The expressions of coefficients in (8) are presented in Appendix B.

By proceeding in a similar manner, the overall transfer function of turbine regulating system of isolated HPP without surge tank is derived from Figures 2(a) and 2(c) and the Laplace transforms of (7), (4)-(6) are as follows:

$$
G(s)=\frac{X(s)}{M_{g}(s)}=-\frac{s\left(b_{2} s+b_{3}\right) / K_{i}}{a_{2} s^{3}+a_{3} s^{2}+a_{4} s+a_{5}} .
$$

Note that (9) can also be obtained from (8) by letting $T_{w y}=0, h_{y 0}=0$, and $T_{F}=0$. The expressions of coefficients in (9) are the special cases of those in (8) when $T_{w y}, h_{y 0}$, and $T_{F}$ are both 0 . 


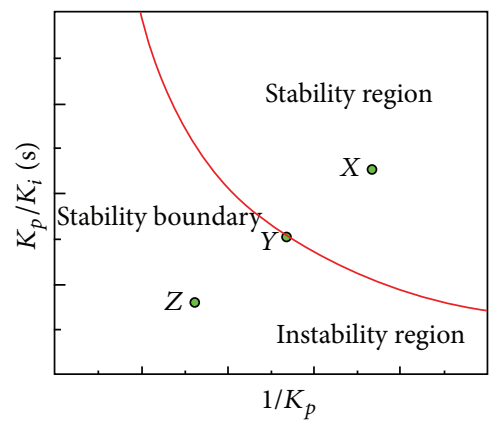

(a) Stability region in the plane of $1 / K_{p}$ and $K_{p} / K_{i}$

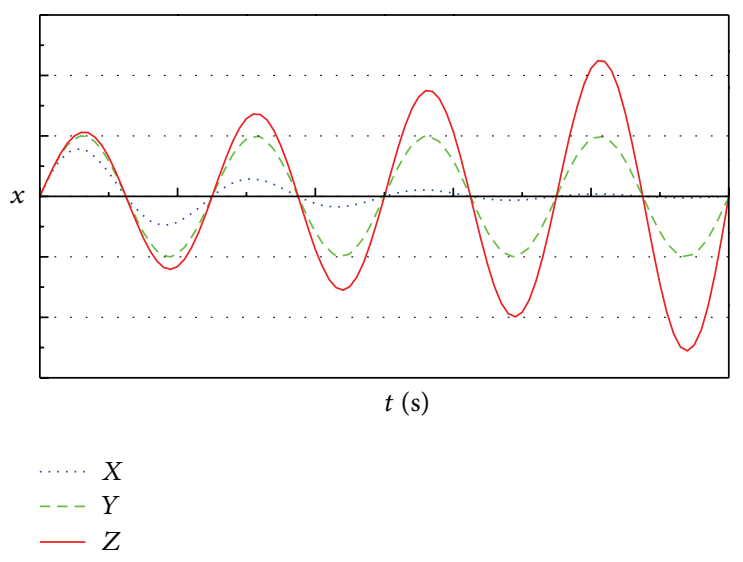

(b) Types of free oscillations corresponding to different regions

FIGURE 3: Stability region of turbine regulating system.

\section{Effect of Penstock on Stability}

Stability reflects the performance of free oscillation of dynamic system that restores to a new equilibrium state after input disturbance vanishes. The free oscillation is divided into three types: damped oscillation, persistent oscillation, and divergent oscillation (shown in Figure 3(b)). On the basis of the definition of Lyapunov on stability [21], the first two types of oscillation are stable and the third one is unstable. However, the stable oscillation is only restricted to damped oscillation in practical projects. This paper uses the latter definition.

3.1. Free Oscillation Equation and Stability Criterion. The stability of regulating system is described by free oscillation equation and discriminated by stability criterion.

3.1.1. Free Oscillation Equation. The following third order and fifth order linear homogeneous differential equations obtained from (9) and (8) are the free oscillation equations of turbine regulating system without surge tank and with surge tank, respectively:

$$
\begin{gathered}
a_{2} \frac{d^{3} x}{d t^{3}}+a_{3} \frac{d^{2} x}{d t^{2}}+a_{4} \frac{d x}{d t}+a_{5}=0 \\
a_{0} \frac{d^{5} x}{d t^{5}}+a_{1} \frac{d^{4} x}{d t^{4}}+a_{2} \frac{d^{3} x}{d t^{3}}+a_{3} \frac{d^{2} x}{d t^{2}}+a_{4} \frac{d x}{d t}+a_{5}=0 .
\end{gathered}
$$

3.1.2. Stability Criterion. By applying Routh-Hurwitz criterion [21], the stability criterions of turbine regulating system represented by (10) and (11) are listed in Table 1.

When the coefficients in (10) satisfy the discriminants $\Delta_{1}>0$ and $\Delta_{2}>0$ simultaneously, the system without surge tank is stable. Similarly, the system with surge tank is stable in the conditions of $\Delta_{1}^{\prime}>0, \Delta_{2}^{\prime}>0$, and $\Delta_{4}^{\prime}>0$.

3.2. Stability Analysis. The stability region is the region that satisfies stability criterion of regulating system. In this paper,
TABLE 1: Stability Criterion.

\begin{tabular}{lc}
\hline $\begin{array}{l}\text { System without surge tank } \\
(10)\end{array}$ & System with surge tank (11) \\
\hline $\begin{array}{l}\Delta_{1}=a_{i}>0(i=2,3,4,5) \\
\Delta_{2}=a_{3} a_{4}-a_{2} a_{5}>0\end{array}$ & $\Delta_{1}^{\prime}=a_{i}>0(i=0,1,2,3,4,5)$ \\
$\Delta_{2}^{\prime}=a_{1} a_{2}-a_{0} a_{3}>0$ \\
$\Delta_{4}^{\prime}=\left(a_{1} a_{2}-a_{0} a_{3}\right)\left(a_{3} a_{4}-a_{2} a_{5}\right)$ \\
$-\left(a_{1} a_{4}-a_{0} a_{5}\right)^{2}>0$ \\
\hline
\end{tabular}

the abscissa and ordinate of coordinate plane are selected as $1 / K_{p}$ and $K_{p} / K_{i}$, respectively, and the stability region is illustrated in Figure 3(a). The corresponding relation between the regions in coordinate plane and the types of free oscillations is shown in Figure 3(b).

This paper takes HPP A as example (basic information is shown in Table 3 of Appendix C) to analyse the effect mechanism of water inertia and head loss of penstock on stability of turbine regulating system with surge tank or not. In order to make sure that the results have universal significance and can be applied to any hydroelectric system, the variation ranges of $T_{w t}$ and $h_{t 0}$ are selected as $0 \sim 4 \mathrm{~s}(4 \mathrm{~s}$ is the limit value of $T_{w t}$ ) and $0 \sim 10 \% H_{r}$, respectively. In addition, the sensitivity analysis of net head is carried out under large amplitude of variation $\left(0.67 \mathrm{H}_{r} \sim 1.33 \mathrm{H}_{r}\right)$ so that the effects of different operating conditions can be revealed.

Aiming at two cases of HPP A (with surge tank of real case and without surge tank of assumed case), the investigation of the effects of $T_{w t}, h_{t 0}$, and $H_{0}$ on stability is proceeded by controlling variable method. The default values of $T_{w t}$, $h_{t 0}$, and $H_{0}$ are $2.0 \mathrm{~s}, 4.0 \mathrm{~m}\left(4.4 \% H_{r}\right)$, and $90 \mathrm{~m}\left(1.00 H_{r}\right)$, respectively. The values of other parameters are as follows: $e_{h}=1.5, e_{x}=-1, e_{y}=1, e_{q h}=0.5, e_{q x}=0, e_{q y}=1, T_{a}=$ $8.34 \mathrm{~s}, e_{g}=0$, and $n=0.9$, in which $n=F / F_{t h}$ is amplification coefficient of sectional area of surge tank, and $F_{t h}$ is critical stable sectional area. 

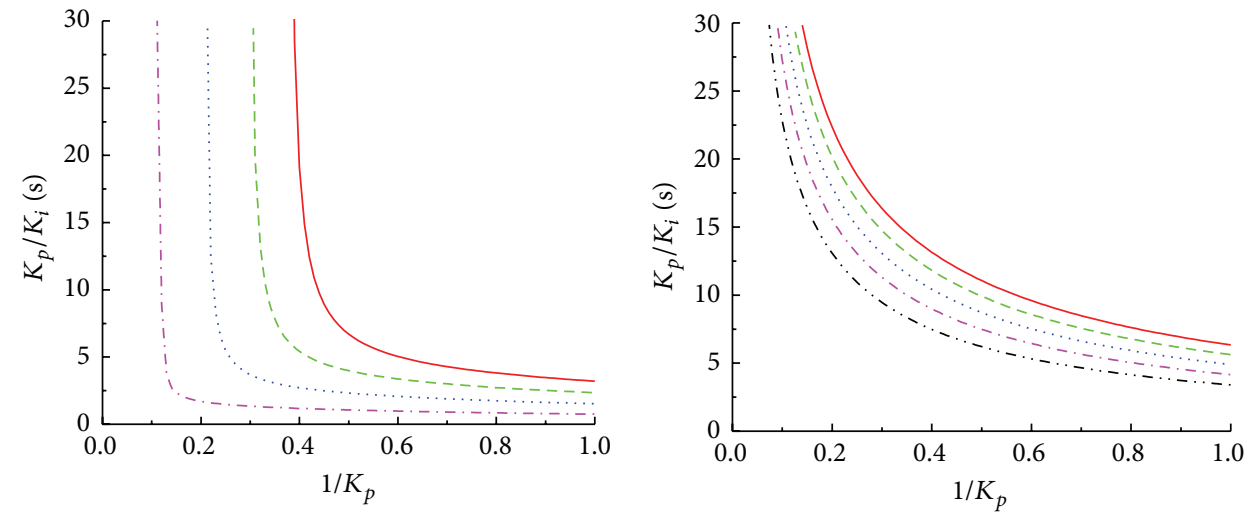

$$
\begin{aligned}
& \cdots T_{w t}=1.0 \mathrm{~s} \quad--T_{w t}=3.0 \mathrm{~s} \\
& \cdots T_{w t}=2.0 \mathrm{~s} \quad-T_{w t}=4.0 \mathrm{~s}
\end{aligned}
$$

(a1) $T_{w t}$

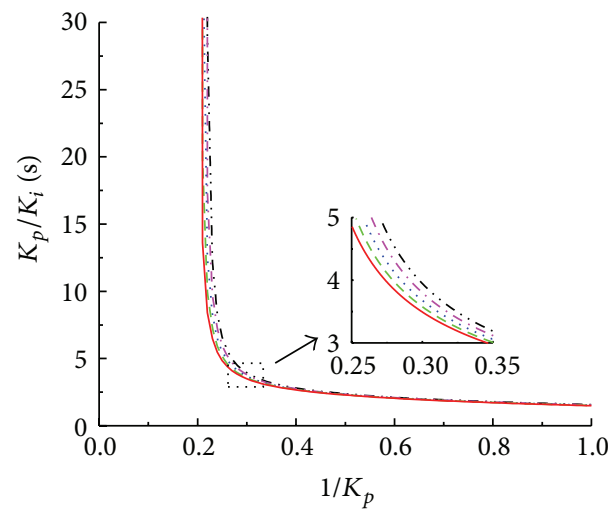

$$
\begin{array}{ll}
\cdots \cdots & h_{t 0}=0.0 \mathrm{~m} \\
\cdots- & h_{t 0}=2.0 \mathrm{~m} \\
\cdots \cdots & h_{t 0}=4.0 \mathrm{~m}
\end{array}
$$

(a2) $h_{t 0}$

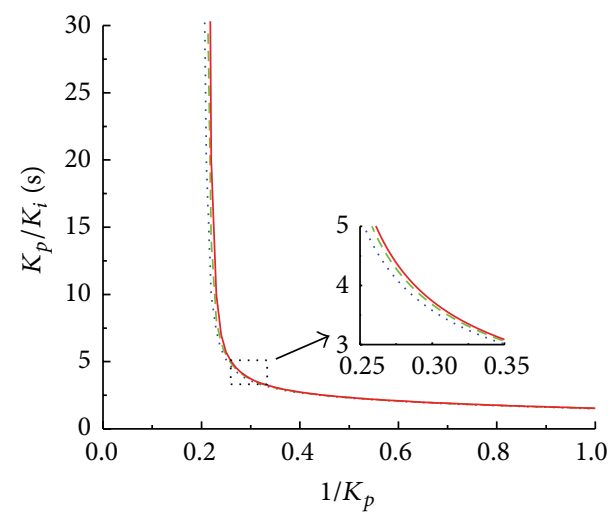

$$
\begin{aligned}
\text { … } H_{0} & =60 \mathrm{~m} \\
---H_{0} & =90 \mathrm{~m} \\
- & H_{0}=120 \mathrm{~m}
\end{aligned}
$$

(a3) $H_{0}$

(a) System without surge tank

$$
\begin{aligned}
& \cdots T_{w t}=0.0 \mathrm{~s} \quad--T_{w t}=3.0 \mathrm{~s} \\
& \cdots-T_{w t}=1.0 \mathrm{~s} \quad-T_{w t}=4.0 \mathrm{~s} \\
& \cdots \cdots T_{w t}=2.0 \mathrm{~s}
\end{aligned}
$$

(b1) $T_{w t}$

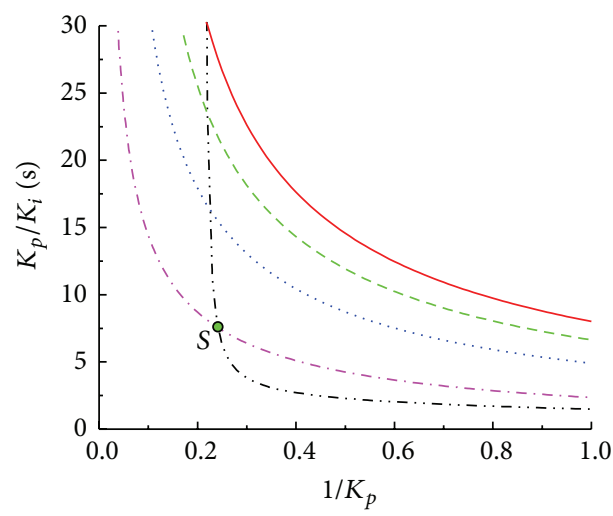

$$
\begin{array}{ll}
\cdots & h_{t 0}=0.0 \mathrm{~m} \quad--h_{t 0}=6.0 \mathrm{~m} \\
\cdots & h_{t 0}=2.0 \mathrm{~m} \quad-h_{t 0}=8.0 \mathrm{~m} \\
\cdots \cdots & h_{t 0}=4.0 \mathrm{~m}
\end{array}
$$

(b2) $h_{t 0}$

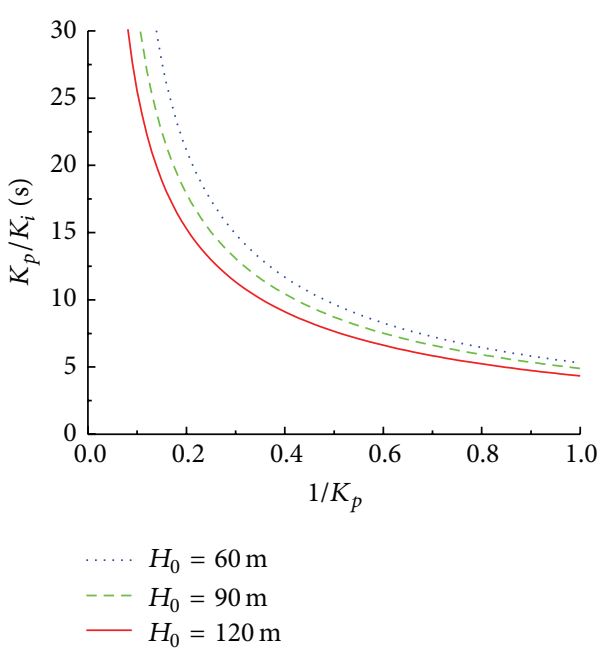

(b3) $H_{0}$

(b) System with surge tank

FIGURE 4: Effects of penstock and net head on stability regions. 
The stability regions of turbine regulating system with surge tank or not are shown in Figure 4.

Figure 4 shows the following.

(1) For the turbine regulating system without surge tank, $T_{w t}$ has significant effect on stability while the effects of $h_{t 0}$ and $H_{0}$ are relatively small. When $T_{w t}$ increases from $1 \mathrm{~s}$ to $4 \mathrm{~s}$, the stability region reduces obviously; that is, the stability of system notably worsens. With the rise of $h_{t 0}$ from $0.0 \mathrm{~m}$ to $8.0 \mathrm{~m}\left(8.9 \% H_{r}\right)$, the stability region enlarges slightly. On the contrary, the stability region diminishes slightly if $H_{0}$ increases from $60 \mathrm{~m}\left(0.67 \mathrm{H}_{r}\right)$ to $120 \mathrm{~m}\left(1.33 \mathrm{H}_{r}\right)$.

(2) For the turbine regulating system with surge tank, $T_{w t}, h_{t 0}$, and $H_{0}$ all have bigger effects on stability, especially, $h_{t 0}$. The stability region enlarges with the decrease of $T_{w t}$ and increase of $H_{0}$. When $h_{t 0}$ decreases from $8.0 \mathrm{~m}\left(8.9 \% H_{r}\right)$ to $2.0 \mathrm{~m}\left(2.2 \% H_{r}\right)$, the stability region enlarges dramatically. It is important to note that there is an intersection point between the stability boundary curves of $h_{t 0}=0.0 \mathrm{~m}$ and $h_{t 0}=$ $2.0 \mathrm{~m}$ (Point $S$ in Figure 4(b2)). In the right side of Point $S$ the stability region diminishes with the increase of $h_{t 0}$ while the change law is just opposite to the left side of Point $S$.

(3) By comparing the turbine regulating system without surge tank and that with surge tank, the following results can be obtained. The effect laws of $T_{w t}$ on the stability of these two systems are consistent and the difference is that the influence on system without surge tank is more sensitive than that with surge tank, while the effect laws of $h_{t 0}$ as well as $H_{0}$ on these two systems are contrary and the influence on system with surge tank is far more sensitive than that without surge tank. When $T_{w t}, h_{t 0}$, and $H_{0}$ change, the variation amplitude of stability boundary curves in the domain of small $1 / K_{p}$ is much greater than that of big $1 / K_{p}$ for system without surge tank; however, the variation amplitudes of stability boundary curves in these two domains are close for system with surge tank.

\section{Effect of Penstock on Regulation Quality}

Regulation quality reflects the rapidity and stationarity of dynamic response of regulating system. The common used dynamic performance indexes that evaluate regulation quality are peak time, settling time, overshoot, and number of oscillation. Regulation quality depends on its own oscillation characteristic of dynamic response [22]. The dynamic response of turbine regulating system is represented by the time response of the frequency of hydroelectric generating unit. Hence, the regulation quality is determined by oscillation characteristic of time response of the frequency in time domain.

4.1. Time Response of the Frequency. The input signal for a step load disturbance can be computed from $M_{g}(s)=m_{g 0} / s$, in which $m_{g 0}$ is relative value of the load step. Substitution of $M_{g}(s)=m_{g 0} / s$ into (9) and (8) yields the following output signals of time response of the frequency for system without surge tank and system with surge tank, respectively:

$$
\begin{aligned}
& X(s)=-\frac{\sum_{i=2}^{3} b_{i} s^{3-i}}{\sum_{i=2}^{5} a_{i} s^{5-i}} \frac{m_{g 0}}{K_{i}}, \\
& X(s)=-\frac{\sum_{i=0}^{3} b_{i} s^{3-i}}{\sum_{i=0}^{5} a_{i} s^{5-i}} \frac{m_{g 0}}{K_{i}} .
\end{aligned}
$$

4.2. Regulation Quality Analysis. By proceeding in a similar manner with stability analysis in Section 3.2, HPP A is also taken as an example to analyse the effect mechanism of water inertia and head loss of penstock on regulation quality of turbine regulating system with surge tank or not. For the case of $10 \%$ load step reduction when the unit operates at rated power output, that is, $m_{g 0}=-0.1$, the time responses of the frequency of the two turbine regulating systems are shown in Figure 5, in which $K_{p}$ and $K_{i}$ are 2.0 and $0.1 \mathrm{~s}^{-1}$, respectively, and other parameters are the same as those in Section 3.2.

Note that the formula of the period of water-level fluctuation in surge tank in frictional "headrace tunnel, surge tank" system is shown in Appendix D.

Figure 5 and Table 2 show the following.

(1) Under step change in load, there are obvious differences of time responses of the frequency between system without surge tank and that with surge tank. The time response of the frequency of system without surge tank is a single property oscillation which is caused by water hammer wave in penstock, and this response has the characteristics of short period, large amplitude, and fast attenuation. The time response of the frequency of system with surge tank is superposed by two oscillations of different properties. In these two oscillations, the one in the beginning time interval of time response of the frequency is called head wave and the other in the follow-up time interval is called tail wave (shown in Figure 5(b1)), of which the former has the same property with the oscillation of system without surge tank and the latter belongs to low frequency forced oscillation caused by water-level fluctuation in surge tank. The period of tail wave is consistent with that of water-level fluctuation in surge tank. Tail wave has the characteristics of long period, small amplitude, and slow attenuation, and it is the main body of time response of the frequency and the principal factor that determines the regulation quality.

(2) For the turbine regulating system without surge tank, like the effects on stability, $T_{w t}$ has significant effect on time response of the frequency while the effects of $h_{t 0}$ and $H_{0}$ are relatively small. When $T_{w t}$ rises, the maximum amplitude, overshoot, and number of oscillation enlarge dramatically and regulation quality worsen obviously. The maximum amplitude and overshoot increase with the rising of $h_{t 0}$ and 
TABLE 2: Characteristic parameters for time responses of the frequency of turbine regulating system with surge tank or not under $m_{g 0}=-0.1$.

\begin{tabular}{|c|c|c|c|c|c|c|}
\hline \multirow{3}{*}{ Types of fluctuation } & \multirow{3}{*}{$\begin{array}{c}\text { System without surge tank } \\
\text { Maximum }\end{array}$} & \multicolumn{4}{|c|}{ System with surge tank } & \multirow{3}{*}{$\begin{array}{c}\text { Water-level fluctuation } \\
\text { in surge tank } \\
\text { Period (s) }\end{array}$} \\
\hline & & \multirow{2}{*}{$\begin{array}{l}\text { Head wave } \\
\text { Maximum }\end{array}$} & \multicolumn{3}{|c|}{ Tail wave } & \\
\hline & & & Amplitude & Attenuation rate & Period (s) & \\
\hline \multicolumn{7}{|l|}{$\bar{T} T_{w t}(\mathrm{~s})$} \\
\hline 0 & l & 0.0318 & 0.0140 & 0.0007 & 323.87 & 313.91 \\
\hline 1 & 0.0337 & 0.0344 & 0.0141 & 0.0007 & 322.21 & 313.91 \\
\hline 2 & 0.0416 & 0.0419 & 0.0142 & 0.0007 & 322.21 & 313.91 \\
\hline 3 & 0.0529 & 0.0534 & 0.0145 & 0.0006 & 322.21 & 313.91 \\
\hline 4 & 0.0666 & 0.0670 & 0.0145 & 0.0006 & 322.21 & 313.91 \\
\hline \multicolumn{7}{|l|}{$h_{t 0}(\mathrm{~m})$} \\
\hline 0 & 0.0395 & 0.0398 & 0.0122 & 0.0010 & 317.33 & 310.72 \\
\hline 2 & 0.0404 & 0.0409 & 0.0132 & 0.0008 & 318.94 & 312.21 \\
\hline 4 & 0.0416 & 0.0419 & 0.0142 & 0.0007 & 322.21 & 313.91 \\
\hline 6 & 0.0427 & 0.0429 & 0.0156 & 0.0006 & 325.55 & 315.87 \\
\hline 8 & 0.0439 & 0.0443 & 0.0172 & 0.0004 & 328.96 & 318.15 \\
\hline \multicolumn{7}{|l|}{$H_{0}(\mathrm{~m})$} \\
\hline 60 & 0.0427 & 0.0426 & 0.0227 & 0.0005 & 356.99 & 342.11 \\
\hline 90 & 0.0416 & 0.0419 & 0.0142 & 0.0007 & 322.21 & 313.91 \\
\hline 120 & 0.0410 & 0.0415 & 0.0105 & 0.0013 & 286.90 & 305.00 \\
\hline
\end{tabular}

TABLE 3: Basic information of actual examples of HPP.

\begin{tabular}{lccccccc}
\hline HPP & Rated power output $N_{r}(\mathrm{MW})$ & Rated head $H_{r}(\mathrm{~m})$ & Rated discharge $Q_{r}\left(\mathrm{~m}^{3} / \mathrm{s}\right)$ & $T_{w y}(\mathrm{~s})$ & $T_{w t}(\mathrm{~s})$ & $h_{y 0}(\mathrm{~m})$ & $h_{t 0}(\mathrm{~m})$ \\
\hline A & 51.28 & 90.00 & 62.70 & 17.75 & 2.33 & 7.57 & 5.53 \\
B & 118.56 & 177.00 & 72.50 & 39.73 & 1.82 & 20.53 & 5.12 \\
C & 610.00 & 288.00 & 228.60 & 23.84 & 1.26 & 12.92 & 2.91 \\
\hline
\end{tabular}

regulation quality worsens as a consequence. If $H_{0}$ increases, the maximum amplitude and overshoot decrease and then regulation quality is improved.

(3) For the turbine regulating system with surge tank, the effect laws of $T_{w t}, h_{t 0}$, and $H_{0}$ on head wave are the same with those on the time response of the frequency of system without surge tank; $T_{w t}$ has almost no influence on tail wave while the influences of $h_{t 0}$ and $H_{0}$ are significant. With the increase of $T_{w t}$, the period of tail wave reduces and the maximum amplitude and attenuation rate of tail wave enlarge. As a result, regulation quality will get better or worse. When $h_{t 0}$ rises, regulation quality notably worsens because of the increase of period and maximum amplitude and the decrease of attenuation rate. In contrast with $h_{t 0}$, the period and the maximum amplitude reduce and attenuation rate enlarges with the rising of $H_{0}$, and the regulation quality notably gets better.

In the high head HPP, pressure fluctuation in penstock and limited speed of guide vane movement are important for the stable and secure operation at the changes of power or frequency, especially at load rejections and emergency shut-down functions. Figure 6 gives the time responses of the guide vane opening $y$ and net head $h$ of turbine regulating system with surge tank or not under $m_{g 0}=-0.1$ corresponding to time response of the frequency $x$.

Figure 6 shows the following.

(1) The change laws of guide vane opening response and net head response of system without surge tank are the same with those of system with surge tank. When the frequency increases (or decreases), the guide vane opening decreases (or increases) to reduce (or rise) the discharge and output power, and then the net head increases (or decreases) because of the reduction (or rising) of discharge.

(2) The amplitude of variation of guide vane opening response is larger than that of net head response, and they are larger than that of time response of the frequency, especially in the system with surge tank. This result indicates that guide vane opening response and net head response are more sensitive than time response of the frequency to load disturbance.

(3) The stability of these three responses is the same, while their regulation qualities are of significant differences. 


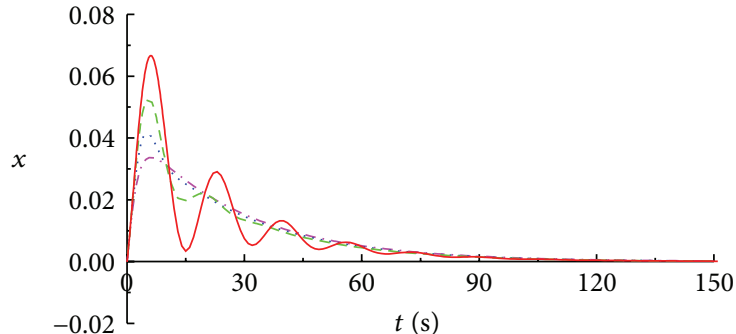

$$
\begin{array}{ll}
\cdots T_{w t} & =1.0 \mathrm{~s} \quad--T_{w t}=3.0 \mathrm{~s} \\
\cdots \cdots & T_{w t}=2.0 \mathrm{~s} \quad-T_{w t}=4.0 \mathrm{~s}
\end{array}
$$

(a1) $T_{w t}$

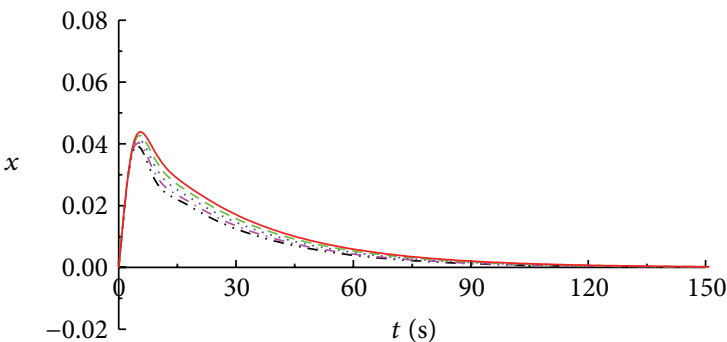

$$
\begin{array}{ll}
\cdots \cdots & h_{t 0}=0.0 \mathrm{~m} \quad--h_{t 0}=6.0 \mathrm{~m} \\
\cdots- & h_{t 0}=2.0 \mathrm{~m} \quad-h_{t 0}=8.0 \mathrm{~m} \\
\cdots \cdots & h_{t 0}=4.0 \mathrm{~m}
\end{array}
$$

(a2) $h_{t 0}$

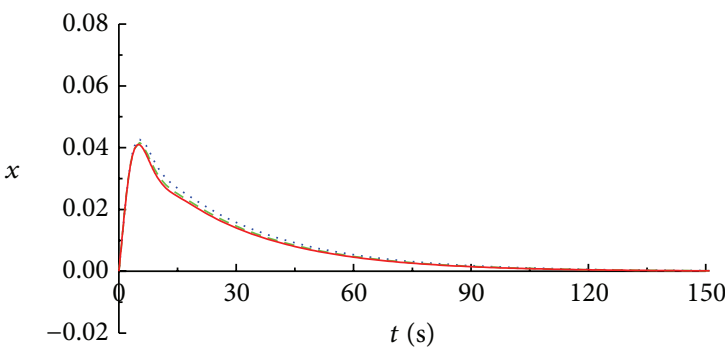

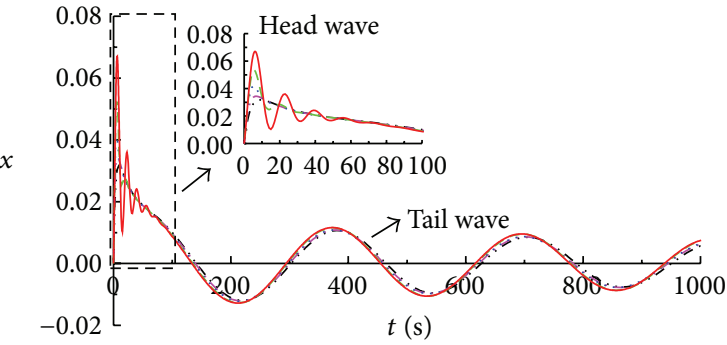

$$
\begin{aligned}
& \cdots T_{w t}=0.0 \mathrm{~s} \quad--T_{w t}=3.0 \mathrm{~s} \\
& \cdots-T_{w t}=1.0 \mathrm{~s} \\
& \cdots \cdots T_{w t}=2.0 \mathrm{~s}
\end{aligned}
$$

(b1) $T_{w t}$

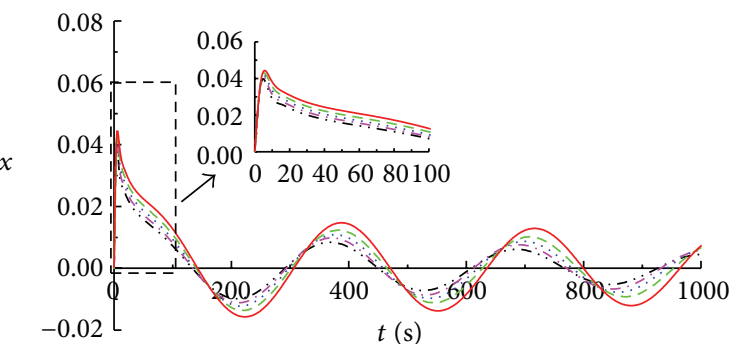

$$
\begin{array}{ll}
\cdots & h_{t 0}=0.0 \mathrm{~m} \quad-\cdots \\
\cdots- & h_{t 0}=6.0 \mathrm{~m} \\
\cdots \cdots & h_{t 0}=4.0 \mathrm{~m}
\end{array}
$$

(b2) $h_{t 0}$

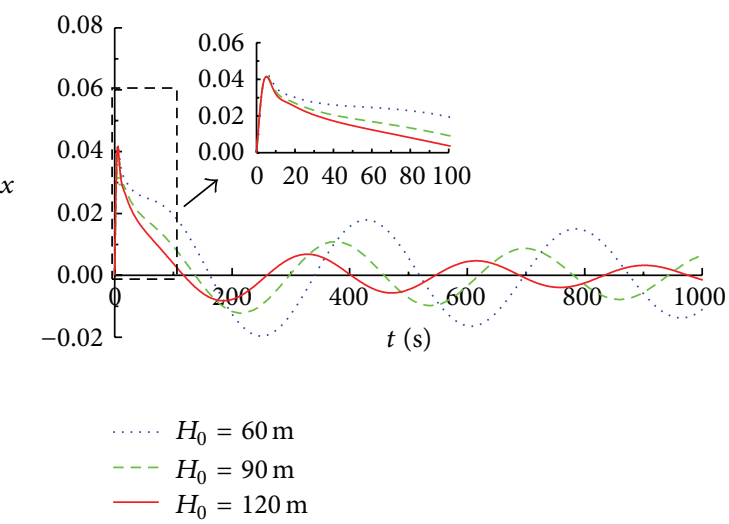

(b3) $H_{0}$

(b) System with surge tank

(a) System without surge tank

FIGURE 5: Effects of penstock and net head on time responses of the frequency.

\section{Effect Mechanism of Water Inertia and Head Loss of Penstock and Its Applications}

5.1. Effect Mechanism of Water Inertia and Head Loss of Penstock. Based on the analyses in Sections 3 and 4, the effect mechanism of penstock is epurated and summarized as follows. The stability and regulation quality of system without surge tank are determined by the dynamic response (e.g., time response of the frequency) which only depends on water hammer wave in penstock. However, for system with surge tank, the dynamic response depending on water hammer wave in penstock and water-level fluctuation in surge tank jointly determines the stability and regulation quality. Specific to the effects of water inertia and head loss of penstock.

Water inertia of penstock is the principal aspect that influences water hammer wave. Hence, the stability and time response of the frequency of system without surge tank, as well as the stability and head wave of system with surge 


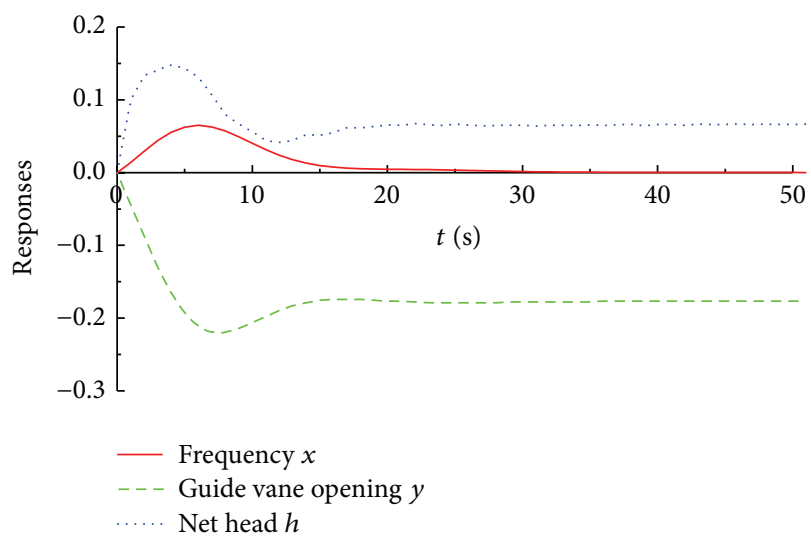

(a) System without surge tank

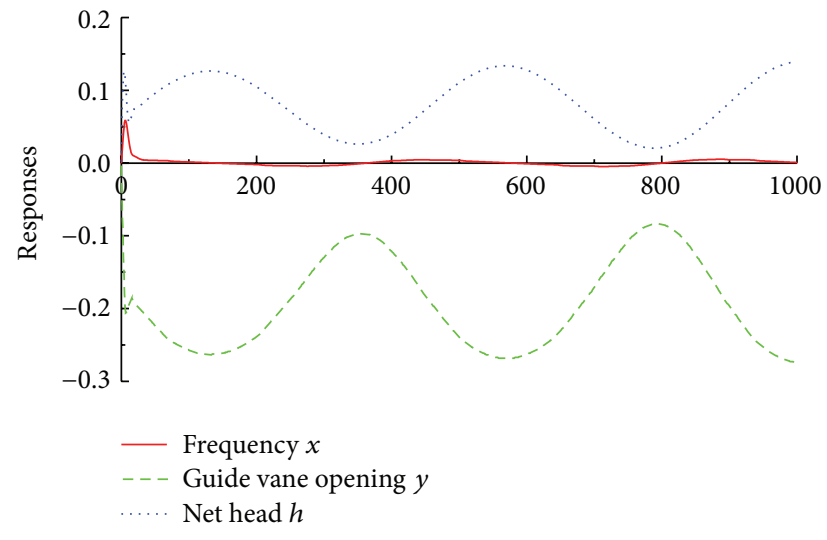

(b) System with surge tank

FIGURE 6: Time responses of the guide vane opening and net head.

tank, are significantly impacted by the water inertia. However, water hammer wave which is low frequency fluctuation has little influence on water-level fluctuation in surge tank. Therefore, there is almost no effect of the water inertia on the tail wave of system with surge tank.

Head loss of penstock is the damping of turbine regulating system and influences the water-level fluctuation characteristic in surge tank mainly by impacting the water flow movement and energy consumption of "surge tank-penstock" subsystem. Hence, the head loss almost has no effect on the stability and time response of the frequency of system without surge tank, while the stability and tail wave of system with surge tank are notably affected. In addition, in the mathematical model of turbine regulating system (Section 2), $h_{t 0}$ is represented in the form of $h_{t 0} / H_{0}$ which indicates that the effect of $H_{0}$ is actualized by serving as the amplification coefficient of $h_{t 0}$ (i.e., $1 / H_{0}$ ). This result reveals the internal cause of the opposite effects of $h_{t 0}$ and $H_{0}$.

\subsection{Application I: Improvements of Stability and Regulation} Quality. According to the effect mechanism of water inertia and head loss of penstock, the stability and regulation quality can be improved specifically. The methods of improvement are the results in Sections 3 and 4. Reversely, in the design of HPP, the effect mechanism can provide theoretical foundation and guidance for reasonable selections of $T_{w t}, h_{t 0}, H_{0}$, $K_{p}$, and $K_{i}$ to guarantee preferable stability and regulation quality.

\subsection{Application II: Construction of Equivalent Model. By} neglecting secondary factors in the complete mathematical model of turbine regulating system based on the effect mechanism of penstock, some equivalent simplified models can be constructed.

5.3.1. Equivalent Model for Stability of System without Surge Tank. For stability of system without surge tank, the water inertia and head loss of penstock are the principal factor and secondary factor, respectively. Hence, if the head loss item

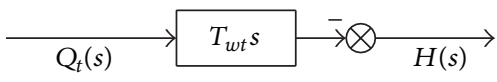

FIGURE 7: Block diagram of pipeline system without surge tank when head loss of penstock is neglected.

is neglected, the original block diagram of pipeline system without surge tank shown in Figure 2(c) is simplified to the block diagram shown in Figure 7. Then the equivalent free oscillation equation of (10) can be obtained by letting $h_{t 0}$ be 0 . This equivalent equation is also third order. HPP B and HPP $\mathrm{C}$ (shown in Table 3 of Appendix C, assumed cases without headrace tunnel and surge tank) are taken as examples to verify the stability of this equivalent third order model and original third order model (i.e., see (10)). The stability regions of these two models are shown in Figure 8. It can be seen that the stability regions of equivalent model and original model are nearly overlapped.

5.3.2. Equivalent Model for Regulation Quality of System with Surge Tank. For regulation quality of system with surge tank, the head loss and water inertia of penstock are the principal factor and secondary factor, respectively. Proceeding similarly as Section 5.3.1, Figure 9 and (14) obtained by neglecting the water inertia item are the equivalent simplified block diagram of pipeline system with surge tank of Figure 2(b) and time response of the frequency of (13), respectively:

$$
X(s)=-\frac{\sum_{i=1}^{3} b_{i} s^{3-i}}{\sum_{i=1}^{5} a_{i} s^{5-i}} \frac{m_{g 0}}{K_{i}} .
$$

Equation (14) is a fourth order response model and its coefficients are the special cases of those in original fifth order response model (see (13)) when $T_{w t}$ is 0 . According to Galois theory [23], original fifth order model has no extract roots formulas. Therefore, it is not only impossible to solve the fluctuation equation of time response of the frequency (i.e., $x=x(t))$ from original fifth order model directly, but also difficult to carry out theoretical analysis. This paper realizes 


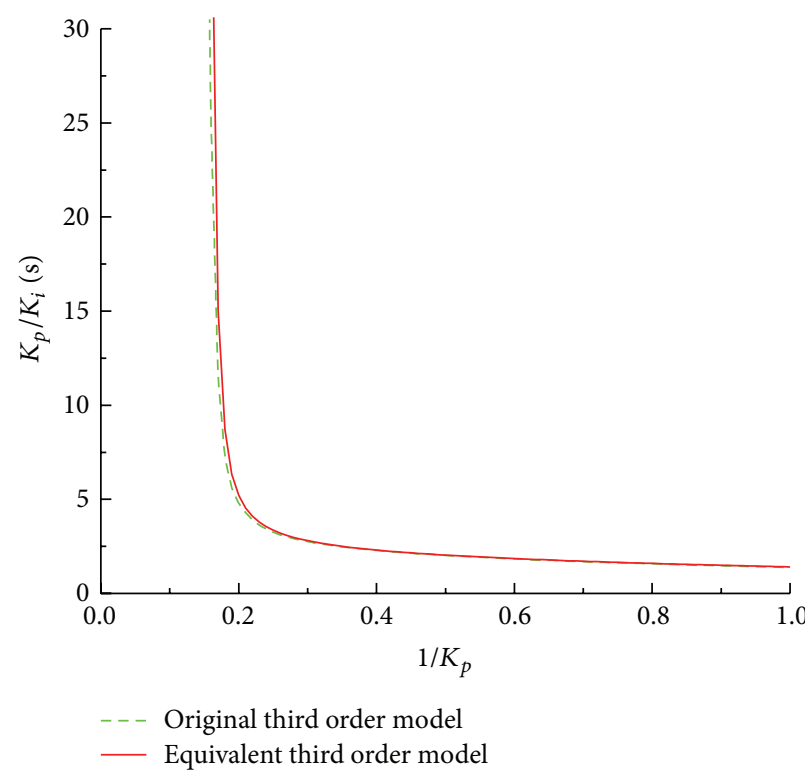

(a) HPP B

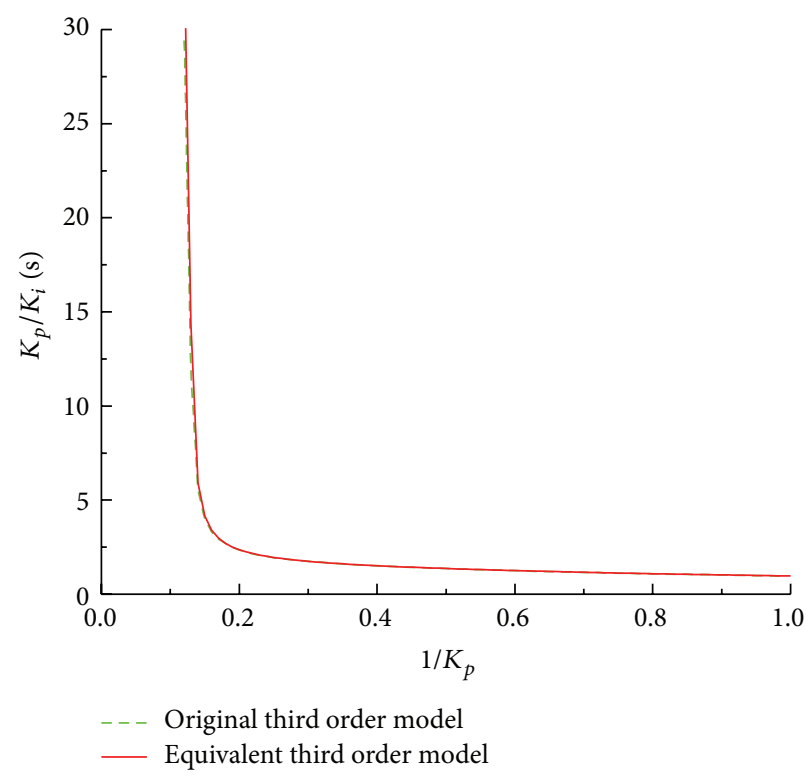

(b) HPP C

FIGURE 8: Comparison of stability regions between equivalent third order model and original third order model.

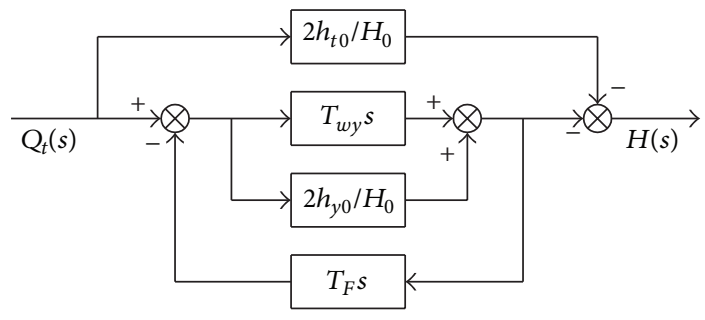

FIGURE 9: Block diagram of pipeline system with surge tank when water inertia of penstock is neglected.

order reduction by using the effect mechanism of penstock and obtains an equivalent fourth order response model which can be theoretically solved. The method and result have great application values.

Figure 10 compares the time responses of the frequency between equivalent fourth order model and original fifth order model using HPP B and HPP C. There is a satisfactory agreement between the time responses of the frequency of these two models. This result indicates that the equivalent fourth order model can represent and replace the original fifth order model.

\section{Conclusions}

Aiming at the turbine regulating system of isolated HPP without surge tank and that with surge tank, this paper studies the effect mechanism of water inertia and head loss of penstock on stability and regulation quality under load disturbance based on the free oscillation equation and time response of the frequency of system. The construction methods of equivalent models for stability and regulation quality are proposed according to the effect mechanism. The major conclusions are summarized as follows.

(1) The stability and regulation quality of system without surge tank are determined by time response of the frequency which only depends on water hammer wave in penstock, while for system with surge tank, the time response of the frequency depending on water hammer wave in penstock and water-level fluctuation in surge tank jointly determines the stability and regulation quality.

(2) Water inertia of penstock mainly affects the stability and time response of the frequency of system without surge tank as well as the stability and head wave of time response of the frequency with surge tank. However, it has almost no effect on the tail wave of time response of the frequency with surge tank.

(3) Head loss of penstock mainly affects the stability and tail wave of time response of the frequency with surge tank rather than the stability and time response of the frequency without surge tank and head wave. The effect of $H_{0}$ on stability and regulation quality which is opposite to that of $h_{t 0}$ is actualized by serving as the amplification coefficient of $h_{t 0}$ (i.e. $1 / H_{0}$ ).

(4) The effect mechanism of penstock can be applied as theoretical foundation and guidance to improve stability and regulation quality.

(5) For stability of system without surge tank, the third order free oscillation equation obtained by neglecting the head loss item of penstock is the equivalent model of original third order free oscillation equation. For regulation quality of system with surge tank, the fourth order response obtained by neglecting 


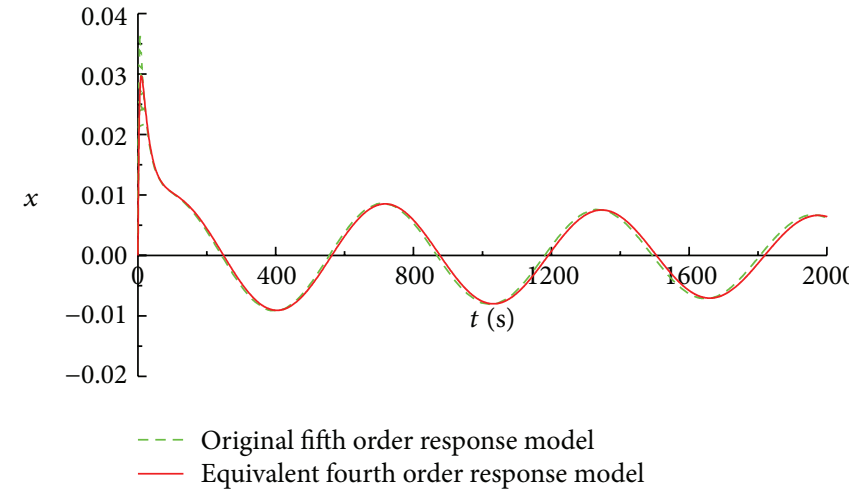

(a) HPP B

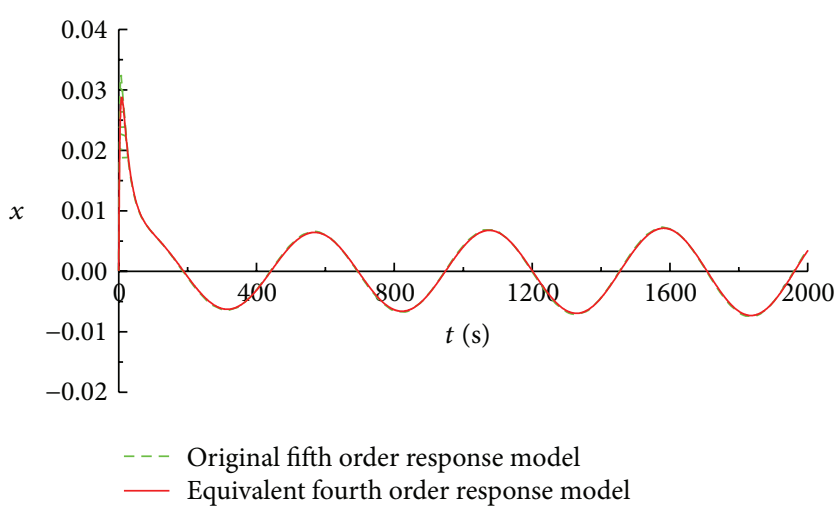

(b) HPP C

FIGURE 10: Comparison of time responses of the frequency between equivalent fourth order model and original fifth order model.

the water inertia item of penstock is the equivalent model of original fifth order response.

\section{Appendices}

\section{A. Definitions of Parameters}

See Nomenclature Section.

Note the following.

(1) $z=\Delta Z / H_{0}, h=\left(H-H_{0}\right) / H_{0}, q_{y}=\left(Q_{y}-Q_{0}\right) / Q_{0}$, $q_{t}=\left(Q_{t}-Q_{0}\right) / Q_{0}, x=\left(n-n_{0}\right) / n_{0}, Y=\left(Y-Y_{0}\right) / Y_{0}$, $m_{t}=\left(M_{t}-M_{t 0}\right) / M_{t 0}$, and $m_{g}=\left(M_{g}-M_{t 0}\right) / M_{g 0}$ are the relative deviations of corresponding variables. The subscript " 0 " refers to the initial value: $Q_{0}=Q_{y 0}=$ $Q_{t 0}, T_{F}=F H_{0} / Q_{0}$.

(2) The six transfer coefficients are defined as follows: $e_{h}=\partial m_{t} / \partial h, e_{x}=\partial m_{t} / \partial x, e_{y}=\partial m_{t} / \partial y, e_{q h}=\partial q_{t} /$ $\partial h, e_{q x}=\partial q_{t} / \partial x$, and $e_{q y}=\partial q_{t} / \partial y$.

(3) $m_{g}$ is actually equal to the relative deviation of load in the isolated operation. Hence, $m_{g}$ is regarded as the load disturbance.

\section{B. Expressions of Coefficients}

The expressions of coefficients in overall transfer function (see (8)) are as follows:

$$
\begin{gathered}
a_{0}=f_{1} f_{9}, \\
a_{1}=f_{1} f_{10}+f_{2} f_{9}+f_{5} f_{12}, \\
a_{2}=f_{1} f_{11}+f_{2} f_{10}+f_{3} f_{9}+f_{5} f_{13}+f_{6} f_{12}, \\
a_{3}=f_{2} f_{11}+f_{3} f_{10}+f_{4} f_{9}+f_{6} f_{13}+f_{7} f_{12}, \\
a_{4}=f_{3} f_{11}+f_{4} f_{10}+f_{7} f_{13}+f_{8} f_{12}, \\
a_{5}=f_{4} f_{11}+f_{8} f_{13},
\end{gathered}
$$

$$
\begin{aligned}
& b_{0}=f_{1} \text {, } \\
& b_{1}=f_{2} \text {, } \\
& b_{2}=f_{3} \text {, } \\
& b_{3}=f_{4} \text {, } \\
& f_{1}=e_{q h} T_{F} T_{w y} T_{w t}, \\
& f_{2}=T_{F}\left[T_{w y}\left(1+e_{q h} \frac{2 h_{t 0}}{H_{0}}\right)+T_{w t} e_{q h} \frac{2 h_{y 0}}{H_{0}}\right] \text {, } \\
& f_{3}=e_{q h}\left(T_{w y}+T_{w t}\right)+T_{F} \frac{2 h_{y 0}}{H_{0}}\left(1+e_{q h} \frac{2 h_{t 0}}{H_{0}}\right) \text {, } \\
& f_{4}=1+e_{q h} \frac{2\left(h_{y 0}+h_{t 0}\right)}{H_{0}}, \\
& f_{5}=T_{F} T_{w y} T_{w t}, \\
& f_{6}=T_{F}\left(T_{w y} \frac{2 h_{t 0}}{H_{0}}+T_{w t} \frac{2 h_{y 0}}{H_{0}}\right) \text {, } \\
& f_{7}=T_{w y}+T_{w t}+T_{F} \frac{2 h_{y 0}}{H_{0}} \frac{2 h_{t 0}}{H_{0}}, \\
& f_{8}=\frac{2\left(h_{y 0}+h_{t 0}\right)}{H_{0}} \\
& f_{9}=\frac{T_{a}}{K_{i}}, \\
& f_{10}=\frac{\left(e_{g}-e_{x}\right)}{K_{i}}+\frac{e_{y} K_{p}}{K_{i}}, \\
& f_{11}=e_{y}, \\
& f_{12}=\frac{e_{h} e_{q x}}{K_{i}}-\frac{e_{h} e_{q y} K_{p}}{K_{i}}, \\
& f_{13}=-e_{h} e_{q y} .
\end{aligned}
$$




\section{Basic Information of Actual Examples of HPP}

See Table 3.

\section{Period of Water-Level Fluctuation in Surge Tank in Frictional “Headrace Tunnel-Surge Tank" System}

Based on reference [1], the free oscillation equation of waterlevel fluctuation in surge tank in frictional "headrace tunnelsurge tank" system is derived as follows:

$$
\frac{d^{2} z}{d t^{2}}+2 \delta \frac{d z}{d t}+\omega^{2} z=0
$$

where $\delta=\left(v_{y 0} / 2\right)\left[2 \alpha g / L_{y}-f_{y} / F\left(H_{0}-2 h_{t 0}\right)\right], \omega=\left(g f_{y} /\right.$ $\left.L_{y} F\right)\left(1-\left(2 h_{y 0} /\left(H_{0}-2 h_{t 0}\right)\right)\right), \alpha=h_{y 0} / v_{y 0}^{2}$, and $v_{y 0}$ is flow velocity in headrace tunnel.

The period of water-level fluctuation in surge tank is obtained according to (D.1): $T_{s t}=2 \pi / \sqrt{\omega^{2}-\delta^{2}}$. If the friction is neglected, the formula of period is simplified to $T_{s t}=$ $2 \pi \sqrt{L_{y} F / g f_{y}}$.

\section{Nomenclature}

\begin{tabular}{|c|c|}
\hline$\Delta Z:$ & $\begin{array}{l}\text { Change of surge tank water level (positive } \\
\text { direction is downward) }\end{array}$ \\
\hline$Q_{y}:$ & Headrace tunnel discharge \\
\hline$n:$ & Unit frequency \\
\hline$M_{t}:$ & Kinetic moment \\
\hline$L_{y}:$ & Length of headrace tunnel \\
\hline$f_{y}:$ & Sectional area of headrace tunnel \\
\hline$h_{y 0}:$ & Head loss of headrace tunnel \\
\hline$T_{w y}:$ & $\begin{array}{l}\text { Water inertia time constant of headrace } \\
\text { tunnel }\end{array}$ \\
\hline$F:$ & Sectional area of surge tank \\
\hline$e_{h}, e_{x}, e_{y}:$ & Moment transfer coefficients of turbine \\
\hline$T_{a}:$ & Unit inertia time constant \\
\hline$K_{p}:$ & Proportional gain \\
\hline$H:$ & Net head \\
\hline$Q_{t}:$ & Penstock discharge \\
\hline$Y:$ & Guide vane opening \\
\hline$M_{g}:$ & Resisting moment \\
\hline$L_{t}:$ & Length of penstock \\
\hline$f_{t}:$ & Sectional area of penstock \\
\hline$h_{t 0}:$ & Head loss of penstock \\
\hline$T_{w t}:$ & Water inertia time constant of penstock \\
\hline$T_{F}:$ & Time constant of surge tank \\
\hline$e_{q h}, e_{q x}, e_{q y}:$ & Discharge transfer coefficients of turbine \\
\hline$e_{g}:$ & Load self-regulation coefficient \\
\hline$K_{i}:$ & Integral gain. \\
\hline
\end{tabular}

\section{Conflict of Interests}

The authors declare that there is no conflict of interests regarding the publication of this paper.

\section{Acknowledgment}

This work was supported by the National Natural Science Foundation of China (Projects nos. 51379158 and 51039005).

\section{References}

[1] M. H. Chaudhry, Applied Hydraulic Transienis, Van Nostrand, New York, NY, USA, 2014.

[2] H. M. Paynter, A Palimpsest on the Electronic Analog Art, GA. Philbrick Researche, Boston, Mass, USA, 1955.

[3] L. M. Hovey, "Optimum adjustment of hydro governors on manitoba hydro system," IEEE Transactions on Power Apparatus and Systems, vol. 81, no. 3, pp. 581-587, 1962.

[4] M. H. Chaudhry, "Governing stability of a hydroelectric power plant," Water Power, vol. 22, no. 4, pp. 131-136, 1970.

[5] H. V. Pico and J. McCalley, "Modeling and analysis of speed controls in hydro-turbines for frequency performance," in Proceedings of the North American Power Symposium, pp. 1-7, Boston, Mass, USA, August 2011.

[6] D. H. Thorne and E. F. Hill, "Extensions of stability boundaries of a hydraulic turbine generating unit," IEEE Transactions on Power Apparatus and Systems, vol. 94, no. 4, pp. 1401-1409, 1975.

[7] D. T. Phi, E. J. Bourque, D. H. Thorne, and E. F. Hill, "Analysis and application of the stability limits of a hydro-generating unit," IEEE Transactions on Power Apparatus and Systems, vol. 100, no. 7, pp. 3201-3211, 1981.

[8] N. S. Dhaliwal and H. E. Wichert, "Analysis of PID governors in multi-machine system," IEEE Transactions on Power Apparatus and Systems, vol. 97, no. 2, pp. 456-463, 1978.

[9] S. Hagihara, H. Yokota, K. Goda, and K. Isobe, "Stability of a hydraulic turbine generating unit controlled by PID governor," IEEE transactions on power apparatus and systems, vol. 98, no. 6, pp. 2294-2298, 1979.

[10] K. A. Naik, P. Srikanth, and A. K. Chande, "A novel governor control for stability enhancement of hydro power plant with water hammer effect," in International Conference on Emerging Trends in Electrical and Computer Technology, pp. 40-45, Tamil Nadu, India, March 2011.

[11] T. Stein, "Frequency control under isolated network conditions," Water Power, vol. 22, no. 9, pp. 320-324, 1970.

[12] F. O. Ruud, "Instability of a hydraulic turbine with a very long penstock," Journal of Engineering for Gas Turbines and Power, vol. 87, no. 3, pp. 290-294, 1965.

[13] M. S. R. Murty and M. V. Hariharan, "Analysis and improvement of the stability of a hydro-turbine generating unit with long penstock," IEEE Transactions on Power Apparatus and Systems, vol. 103, no. 2, pp. 360-367, 1984.

[14] O. H. Souza and N. Barbieri, "Study of hydraulic transients in hydropower plants through simulation of nonlinear model of penstock and hydraulic turbine model," IEEE Transactions on Power Systems, vol. 14, no. 4, pp. 1269-1272, 1999.

[15] C. K. Sanathanan, "Accurate low order model for hydraulic turbine-penstock," IEEE Transactions on Energy Conversion, vol. 2, no. 2, pp. 196-200, 1966.

[16] G. I. Krivehenko, E. V. Kwyatkovskaya, A. E. Lyubitsky, and S. V. Ostroumov, "Some special conditions of unit operation in hydropower plant with long penstocks," in Proceedings of 8th Symposium of IAHR Section for Hydraulic Machinery, Equipment and Cavitation, pp. 465-475, Leningrad, Russia, September 1976. 
[17] L. Fu, J.-D. Yang, H.-Y. Bao, and J.-P. Li, "Generator unit frequency fluctuations of hydropower station with surge tank under load disturbance," Journal of Hydraulic Engineering, vol. 39, no. 11, pp. 1190-1196, 2008.

[18] L. Fu, J. P. Li, J. D. Yang, and H. Y. Bao, "Research on dynamic quality of governing system of hydropower station with tailrace surge tank," Journal of Hydroelectric Engineering, vol. 29, no. 2, pp. 163-176, 2010.

[19] V. L. Streeter and E. B. Wylie, Fluid Transients, McGraw-Hill, New York, NY, USA, 1978.

[20] IEEE Working Group, "Hydraulic turbine and turbine control models for system dynamic studies," IEEE Transactions on Power Systems, vol. 7, no. 1, pp. 167-179, 1992.

[21] G. F. Franklin, D. Powell, and A. E. Naeini, Feedback Control of Dynamic Systems, Prentice Hall, Upper Saddle River, NJ, USA, 2009.

[22] S. P. Wei, Hydraulic Turbine Regulation, Huazhong University of Science and Technology Press, Wuhan, China, 2009.

[23] J. A. Gallian, Contemporary Abstract Algebra, Cengage Learning, Boston, Mass, USA, 2009. 


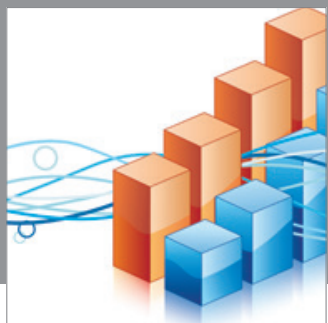

Advances in

Operations Research

mansans

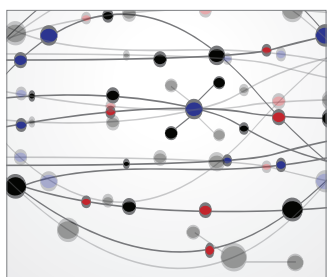

The Scientific World Journal
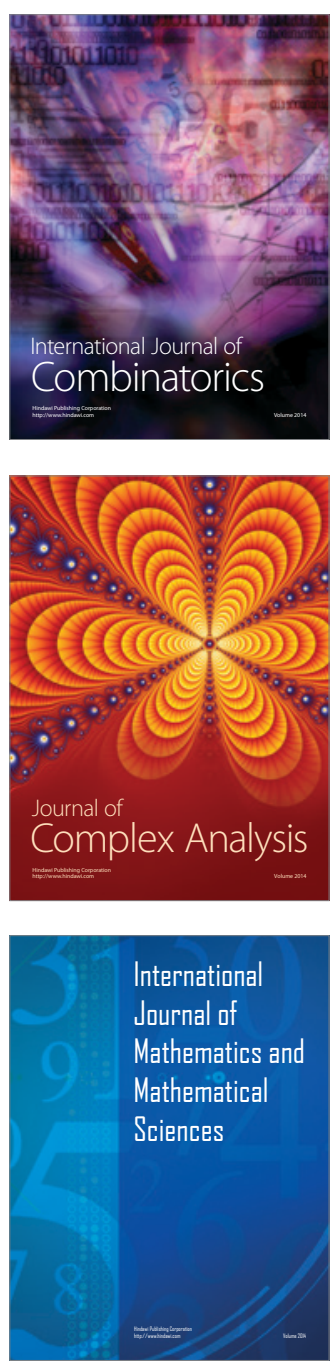
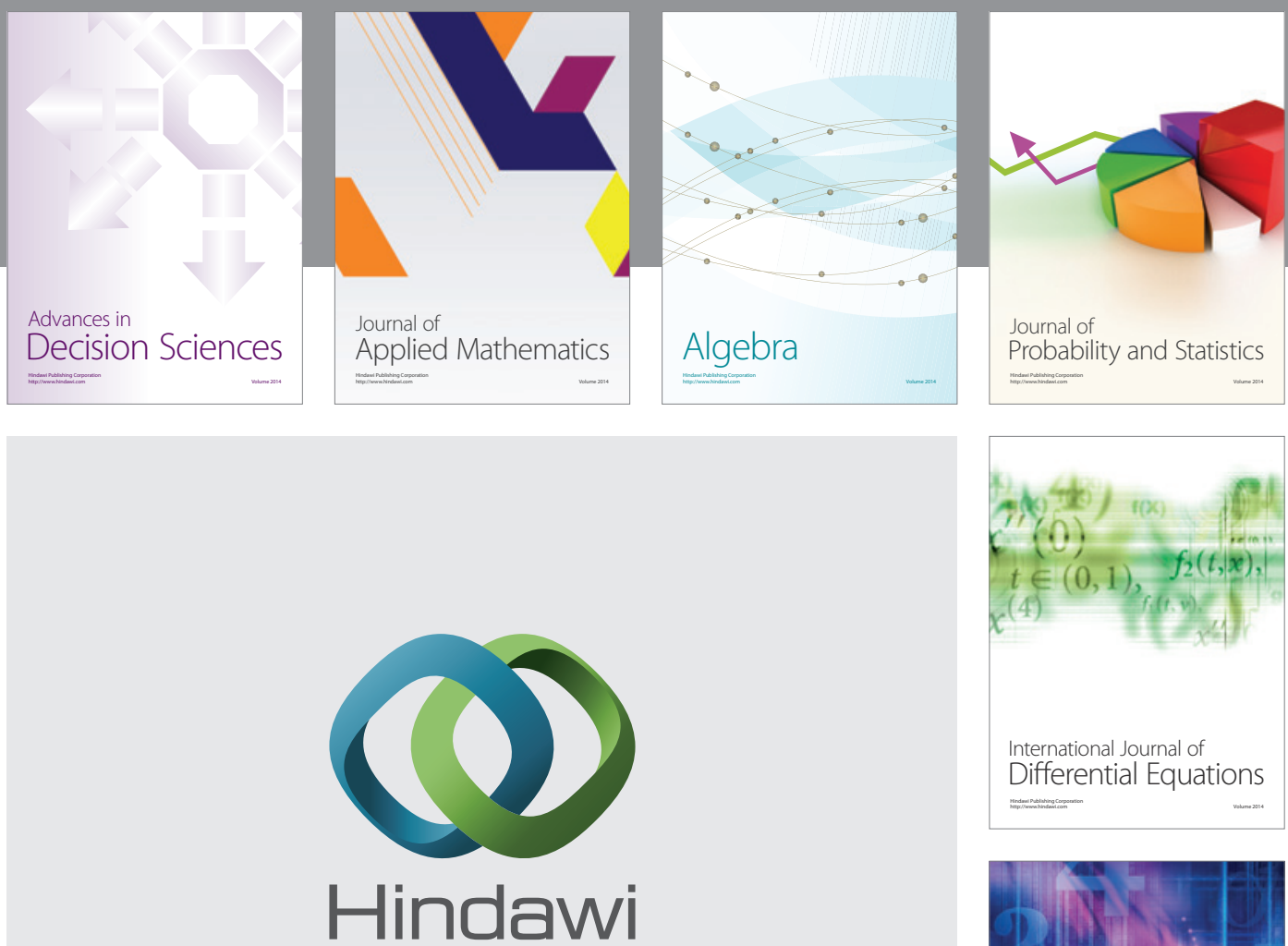

Submit your manuscripts at http://www.hindawi.com
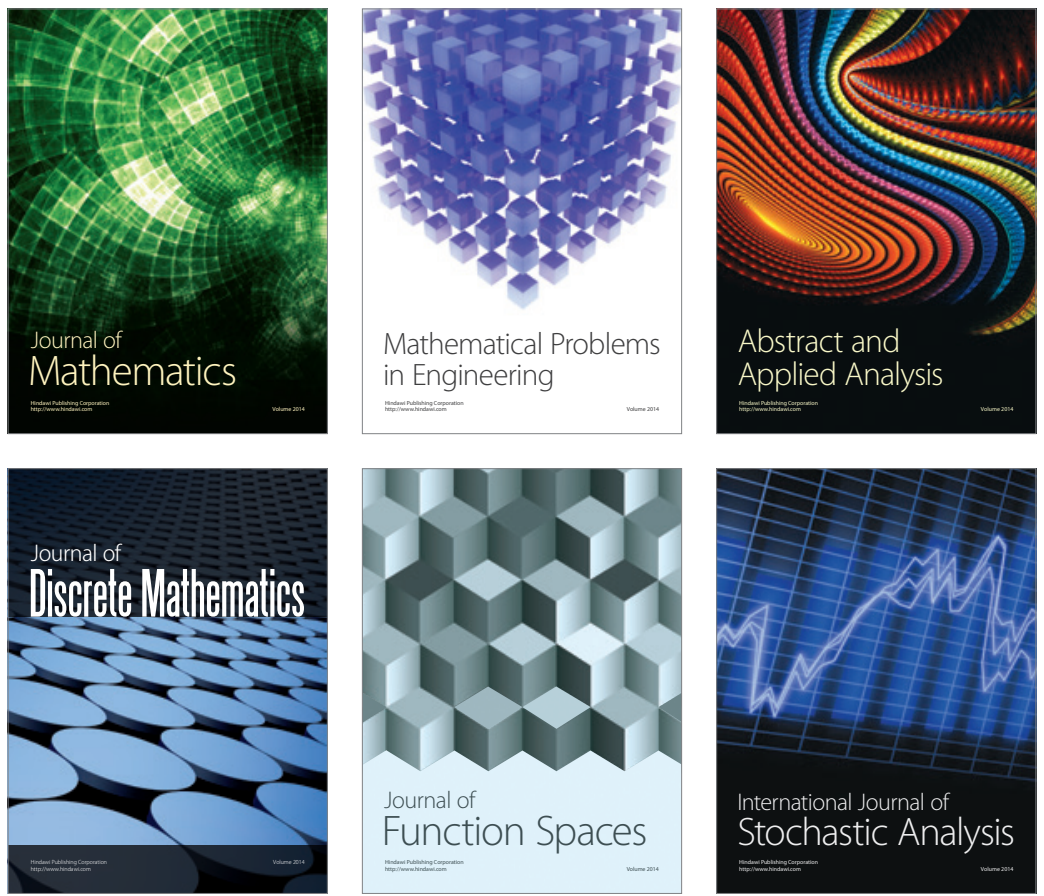

Journal of

Function Spaces

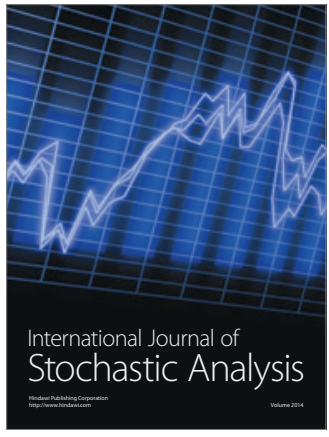

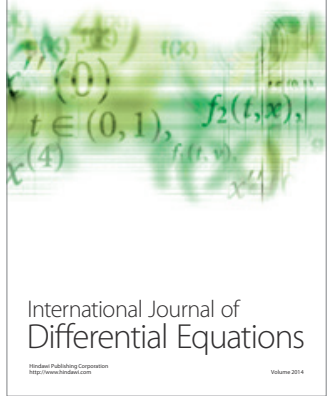
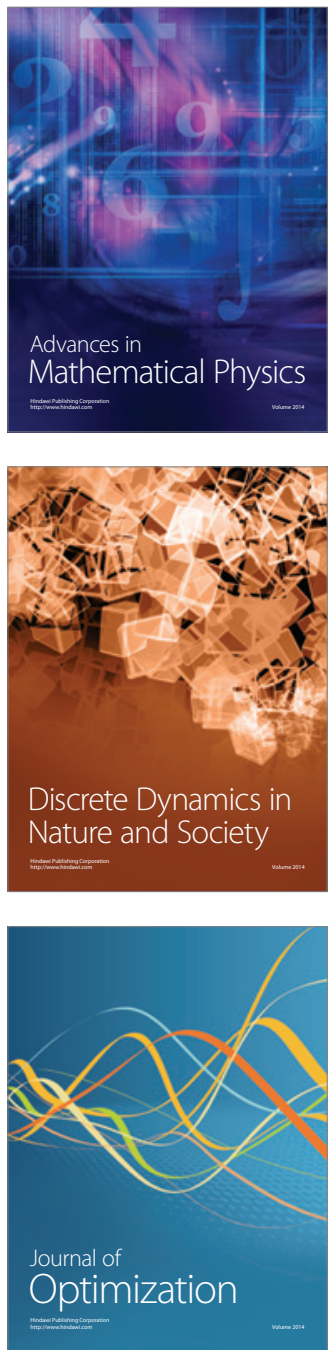